\title{
Mass spectrometry for the detection of potential psychiatric biomarkers
}

\author{
Armand G Ngounou Wetie', Izabela Sokolowska' ${ }^{1}$, Kelly Wormwood ${ }^{1}$, Katherine Beglinger ${ }^{1}$, Tanja Maria Michel ${ }^{2}$, \\ Johannes Thome ${ }^{2,3}$, Costel C Darie ${ }^{1}$ and Alisa G Woods ${ }^{1,4^{*}}$
}

\begin{abstract}
The search for molecules that can act as potential biomarkers is increasing in the scientific community, including in the field of psychiatry. The field of proteomics is evolving and its indispensability for identifying biomarkers is clear. Among proteomic tools, mass spectrometry is the core technique for qualitative and quantitative identification of protein markers. While significant progress has been made in the understanding of biomarkers for neurodegenerative diseases such as Alzheimer's disease, multiple sclerosis and Parkinson's disease, psychiatric disorders have not been as extensively investigated. Recent and successful applications of mass spectrometry-based proteomics in fields such as cardiovascular disease, cancer, infectious diseases and neurodegenerative disorders suggest a similar path for psychiatric disorders. In this brief review, we describe mass spectrometry and its use in psychiatric biomarker research and highlight some of the possible challenges of undertaking this type of work. Further, specific examples of candidate biomarkers are highlighted. A short comparison of proteomic with genomic methods for biomarker discovery research is presented. In summary, mass spectrometry-based techniques may greatly facilitate ongoing efforts to understand molecular mechanisms of psychiatric disorders.
\end{abstract}

Keywords: Mass spectrometry, Biomarker, Psychiatry, Proteomics

\section{Review}

Recently, there have been increased efforts to address psychiatric disorders at the molecular level to understand the pathophysiology and molecular mechanisms involved. A major step has been the effort to discover putative biomarkers specific to psychiatric disorders $[1,2]$. Biological markers (biomarkers) are measurable physiological indicators of disease or a disorder and bear a tremendous potential for diagnosis and treatment monitoring. Biomarker research employs mainly "omic" technologies (genomics, transcriptomics and proteomics) as shown for example, in the transcriptomics profiling of psychosis or mood disorders as well as the proteomic profiling of bipolar disorder [3-5]. Though genomics and transcriptomics were among the first tools used, they are being increasingly substituted by

\footnotetext{
*Correspondence: awoods@clarkson.edu

'Biochemistry and Proteomics Group, Department of Chemistry and Biomolecular Science, Clarkson University, 8 Clarkson Avenue, Potsdam, NY 13699-5810, USA

${ }^{4}$ Neuropsychology Clinic and Psychoeducation Services, SUNY Plattsburgh, 101 Broad St, Plattsburgh 12901, NY

Full list of author information is available at the end of the article
}

proteomics. However, all approaches have individual as well as common advantages and challenges. One collective challenge of both proteomics and genomics lies in the confirmation or validation of identified proteins [6]. Regardless of the approach, the ultimate goal is the discovery of a list of valid, reliable and selective biomarkers.

In this review, we highlight the contribution of proteomics, especially of mass spectrometry (MS) to biomarker discovery research for psychiatric disorders. Proteomics have been of considerable benefit to other disciplines, which suggests that this approach may also be of great interest to psychiatry. For example proteomic analysis is used clinically to identify bacterial subtypes in cystic fibrosis [7], cystitis [8] and septic shock [9], directing treatment. Other clinical uses of proteomics/MS include measurement of renal function [10] and newborn screening for a variety of disorders [11,12]. Proteomic biomarker discovery holds great promise in cancer research for clinical diagnostics, based on the identification of new cancer biomarkers that might open new roads to improved diagnosis and treatment [13-15]. Phosphorylated salivary tau can be detected in people

\section{Biomed Central}


with Alzheimer's disease using proteomic methodology, suggesting diagnostic potential [16]. These are but a few examples illustrating the clinical use and potential of MS-based proteomics.

Our intention is to speak to all involved partners in psychiatric research: psychiatrists, neuroscientists, proteomic researchers in order to bring them together to find answers to some of the questions raised here. Therefore, we first describe the basics of psychiatric disorders and of mass spectrometry, before looking at the connection between both disciplines.

\section{Example biomarkers in psychiatric disorders}

Biomarkers are not routinely used for clinical detection of psychiatric disorders while other widespread medical conditions such as diabetes and heart disease are identified and monitored using several markers [17-19]. There have been numerous studies pointing towards genetic and epigenetic etiologies for psychiatric disorders. By nature, psychiatric disorders may have a concerted pathway that orchestrates the down-regulation of multiple genes through epigenetic mechanisms. For instance, DNA methylations or histone modifications in combination with GABAergic and glutamatergic gene promoters are proposed to be critical elements in the pathogenesis of schizophrenia and bipolar disorder as demonstrated by decreased protein levels of GABA-ergic neuronal markers (reelin, RELN and glutamic acid decarboxylase 67, GAD67) [20-23]. Additionally, it has been suggested that polymorphisms in $A D R A 2 A$ (alpha-2A adrenergic receptor), $D R D 3$ (dopamine receptor D3), $D B H$ (dopamine $\beta$-hydroxylase) and SNAP-25 (25 kDa synaptosomalassociated protein) are individually or collectively risk factors for schizophrenia [24-27]. As just discussed, there are many potential genetic sources from which biological markers could be retrieved in psychiatric disorders. However, non-genomic biomarkers, such as protein/peptide biomarkers, also hold promise.

Due to their broad variety, psychiatric disorders have been hypothesized to be associated with the dysfunction of many biological pathways and networks. For example, impairment of the corticotropin releasing factor (CRF) system is proposed to contribute to symptoms in psychiatric disorders such as depression, obsessive compulsive disorder, post-traumatic stress disorder and substance use disorders [28-32]. Depression has been associated with low plasma levels of antioxidants such as vitamin E, zinc, glutathione (GSH), coenzyme Q10, selenium [33-38].

Dopamine (DA) and noradrenaline (NE) have been proposed to play a major role in modulating high-level executive functions that are impaired in attention-deficit/ hyperactivity disorder (ADHD), for example planning and attention, functions related to fronto-striato-cerebellar circuits (ADHD) [39]. Dopaminergic disturbances have also been posited to underlie the hyperactivity observed in ADHD, likely along with other neurotransmitter systems [40]. Reflecting a possible disturbance in the dopaminergic system, dopamine transporter (DAT) levels are increased in individuals with ADHD [39,41]. A recent meta-analysis confirms that peripheral markers related to the dopaminergic and noradrenergic systems (as well as additional markers such as zinc and cortisol), may be of future use for ADHD diagnosis and treatment [42].

A current common approach in mass spectrometric characterization of proteins is differential gel-based quantitative proteomics $[43,44]$. It consists of separating samples, (from subjects with disorders and unaffected controls), by gel electrophoresis (usually 2D-gel electrophoresis). Gel bands are then analysed by tryptic digestion and LC-MS/MS for protein identification and quantification. Results are often validated by western blot or ELISA. Using this approach (2D-PAGE and LCQ DECA XP PLUS ion trap mass spectrometer), Ditzen and colleagues identified glyoxalase I (GLX1) and enolase phosphatase (EP) as protein markers that could be risk markers for anxiety in a mouse model of trait anxiety [45]. A separate study utilized this technique to identify 59 potential biomarkers in cerebral cortex and 11 in amygdala in post-mortem brain tissue from suicide victims [46]. Several of these proteins were already proposed as psychiatric protein biomarkers. In another study, focusing on major depressive disorder (MDD) in a rat model, 27 potential protein markers with roles in neurogenesis, oxidative metabolism, transcription and signal transduction, were identified by $2 \mathrm{D}$-gel and MALDI-TOF-MS [47]. Shotgun proteomics (explained later) was also employed for the study of brain tissue of samples from MDD patients using SDS-PAGE and nanoHPLC-MS ${ }^{\mathrm{E}}$ (Q-TOF MS) and produced a possible means for categorizing different subtypes of MDD patients based on proteomic profile patterns [48]. These protein fingerprints resulted from significantly, differentially-expressed proteins between subgroups of MDD patients (with and without psychosis) as well as between MDD subjects and healthy controls. Differentiallyexpressed proteins between MDD patients and healthy controls were those involved in metabolism, transport, cell communication and signaling, cell growth and maintenance, protein metabolism and regulation of nucleic acid metabolism. The use of biomarkers to diagnose depression is of great interest and promise, particularly to direct the selection of therapies. However, further studies are needed before proteomics can be used clinically for depression [49].

The discovery of potential biomarkers for depression could be expanded to other related psychiatric disorders since depression is comorbid with many psychiatric, 
neurodegenerative and general medical conditions [28]. A proteomic study reported the association of protein markers of MDD with neurodegenerative diseases such as Huntington and Alzheimer as well as schizophrenia confirming some sense of commonality among neurological and psychiatric disorders at the molecular level [27]. Interestingly, this connection is already observed at the symptomatic level as neuropsychiatric disorders overlap in their symptoms. In this regard, there is a need for identification of a signature of a set of biomarkers rather than relying on a few markers $[6,50]$.

\section{Mass spectrometry}

Proteomics is a fast-rising and promising field with new developments and improvements still taking place. As mentioned, one core method in proteomics is MS. For MS analysis of proteins, proteins are initially separated (biochemically fractionated) via a variety of methods, for example, electrophoresis or chromatography [2]. Once fractionation has been performed, proteins are analysed by MS. A mass spectrometer is made of three main parts: ionization source, mass analyser and detector. The protein sample is ionized using an ionization source. The sample then travels through a mass analyser according to the mass over charge $(\mathrm{m} / \mathrm{z})$. The ionized sample then hits the detector, where spectra are recorded. Spectra serve as protein "fingerprints" that can be used to identify proteins, for example. For a more detailed description of MS tailored to those working in psychiatric research, the reader may refer to Woods et al., 2012 [2].

Due to high-performing MS instruments, simplified analytical workflows and versatile data analysis, mass spectrometry is applicable to almost every area of the life sciences and potentially even far beyond [51-54]. The two most common ionization methods are electrospray ionization (ESI) and matrix-assisted laser desorption/ ionization (MALDI). Currently a multitude of analyzers exist for different types of applications, including, quadrupole (Q), time-of-flight (TOF) and ion trap (IT). Traditionally, MALDI sources are coupled with TOF or TOF/TOF mass analyzers due to their pulse mode of action.

In shotgun proteomics, liquid chromatography (LC) is coupled to mass spectrometry for identification of proteins. In this case, ESI is the ionization mode preferred for the characterization of biomolecules, ionic and very labile organic and organometallic compounds though LC-MALDI-MS is also an eventuality $[55,56]$. Bottomup proteomics represents the case where samples are first digested to generate peptides which can then be analyzed by mass spectrometry while top-down proteomics designate a method where the mass of the entire protein is being measured by a mass spectrometer followed by its sequencing. The main advantage of LC-MALDI-MS over LC-ESI-MS is the robustness of LC-MALDI-MS in resisting to very harsh LC conditions (lower suppression effects) and the high mass-to-charge $(\mathrm{m} / \mathrm{z})$ range of the TOF mass analyzer. The disadvantage of LC-MALDI-MS is the difficulty of spotting directly from the LC apparatus. However, LC-MALDI is only rarely used.

With MS, proteins can be identified by measuring the $\mathrm{m} / \mathrm{z}$ of gas phase ions. We distinguish between gelbased, one-dimensional and two-dimensional gel electrophoresis mass spectrometry (1-DE, 2-DE and MS) [57-64] and non-gel based liquid chromatography/mass spectrometry (LC/MS). In 2-DE, proteins are separated in a first dimension according to their charge or isoelectric point ( $\mathrm{pI}$ ) and in a second dimension depending on their molecular weight $[65,66]$. For visualization of protein bands, the gel can be stained either with the dye coomassie blue or silver stained or by fluorescently labeling the samples before 2-DE. For mass spectrometry analysis, gel bands are removed, and undergo several other steps to generate peptides in bottom-up and shotgun proteomics $[51,53,67,68]$. Compared to LC/MS, 2 -DE methods are more reproducible and robust. However, 2-DE methods are very labor-intensive and not very suitable for hydrophobic, very large or small, basic proteins and complex sample mixtures. However, the weaknesses of 2-DE methods represent the strengths of LC/MS-based methods. LC-MS methods are appreciated for their ability in the analysis of very complex protein samples and extreme proteins (e.g. membrane proteins) and therefore offer better proteome coverage in comparison to 2-DE-based techniques.

For quantification, a label-free or label-based [69] approach can be selected. In general, quantitation is carried out with internal standards which are added to the sample prior to any sample preparation step in order to exclude any variations resulting from the sample preparation. Non-gel, label-based approaches consist in labeling peptides prior to LC separation using mostly the three following techniques: 1) isobaric tags for relative and absolute quantitation, iTRAQ (iTRAQ ${ }^{\circ}$ Applied Biosystems, AB Sciex, Foster City, CA, USA) [70,71]; 2) isotope-coded affinity tags, ICAT [72] and 3) stable isotope labeling of amino acids in cell culture, SILAC $[53,73,74]$. These internal isotopically labeled analogs have the same physico-chemical properties, meaning same retention time, fragmentation pattern and extraction efficiency as their endogenous sample-intrinsic counterparts but differ in their mass shift as a result of the incorporation of heavy or light isotopes in their structure. However, isotopically labeled analogs present some limitations due to their targeted chemistry (e.g. cysteines for ICAT, intensive sample separation and 
longer MS run time). In label-free approaches (e.g. spectral counting), quantitation is based on the number of spectra generated for a reference protein or peptide. Though mostly reported for neurodegenerative proteomic studies $[71,75,76]$, these quantitative techniques can also be extended to psychiatric disorders. Another MS-based quantitation approach that is commonly applied is the multiple-reaction monitoring (MRM) technique that is possible on triple quadrupole, linear ion trap MS instruments. MRM is a robust multiplexed assay for the accurate and sensitive determination of protein expression levels and post-translational protein modifications [77]. Instrument-wise, MALDI is typically coupled to QqQ mass analyzers resulting in fast and sensitive quantitation [78] that is thought to be able to challenge established LC-ESI-MS methods in term of linearity, limit of quantitation, precision and accuracy [79].

Due to the considerable amount of data generated during a proteomics experiment and the need to extract as much information as possible from these data, the field of bioinformatics has become an important tool in the discovery of biomarkers by proteomics methods and has been further improved recently [80,81]. The same can be said of online protein databases (Expasy or HPRD), search engines (X! Tandem, MASCOT, Sequest), data management repositories (PRIDE, GPMdb), data exploration and mining tools (Ingenuity pathways analysis IPA, GOMiner, ProteinLounge, Scaffold, ProteinLynx Global Server). To date, proteomics has been more frequently employed in neurodegenerative disorders than psychiatric [82] and can and should be expanded to psychiatric disorders [4].

\section{Comparison of MS-methods with classical biomarker discovery techniques}

With the completion of the Human Genome Project and the extensive progress made in the field of genomics together with the possible genetic etiology of some psychiatric disorders, genetics and molecular biology represent one of the predominant methods of psychiatric biomarker discovery. Using chromosome microarray with probes for both copy number variants and single nucleotide polymorphisms (SNPs), determination of disorder-underlying genes and segmental deletions or duplications is possible. Newly developed methods such as exome sequencing enable detection of SNPs, gene regulatory sequences and mutations of protein coding genes that could be the root of a psychiatric disorder. However, genomics have some limitations. For example, genomic methods cannot distinguish splice variants or proteins with post-translational modifications.

Though genomics was originally the state of the art discipline for psychiatric biomarker discovery; one can notice the shift that has been taking place in the last decade from genomics- to proteomics-based techniques [26,83-91]. This shift may be due in part to the fact that changes at the mRNA level are not necessarily reflected at the protein level $[92,93]$. Changes at the protein level may reflect disorder processes that cannot be detected at the genomic level. Genomic and proteomic information may be complementary, contributing to more of a systems approach to understanding the biology of psychiatric disorders [1].

One advantage of genetics in biomarker discovery is their superior high-throughput. The amount of mRNA or SNPs that can be analyzed at once is in the tens of thousands for genetic studies compared to few thousand for proteomics. Also, due to the non-translation of some transcripts and the non-secretion of some proteins, transcript rather than protein levels are chosen to be monitored. Finally, the isolation of RNA from blood does not require refrigeration in contrast with plasma and serum samples and is RNA less susceptible to degradation [94].

In some cases, it would be interesting to pursue both genomics and proteomics works to seek confirmation or complementarity of results. Genomic markers and protein markers may ultimately play interesting and possibly complementary roles in psychiatric diagnosis, since genomic information may indicate disorder susceptibility. Due to the ever-changing nature of proteins, proteomic information is more likely to allow for monitoring of certain aspects of a disorder, such as severity and response to treatment. Multiple markers obtained using different data-collection approaches (such as genomic, proteomic, neuroanatomical, brain activity patterns, etc.) comprising a biomarker signature, could aid differential diagnosis, particularly since individual markers are likely to overlap amongst psychiatric syndromes. Indeed, a systems approach to neuropsychiatric disorders has been recently proposed, which would address the multifactorial aspects and complexity of psychiatric problems [1], which would include a consideration of environment, experience and behavior as well as the data measurements listed above. Mass spectrometry and proteomics have the potential to be major components of such an approach.

\section{Discussion}

There are many challenges and stumbling blocks that need to be addressed for mass spectrometry to develop its full potential in psychiatric biomarker research. It is now well known that more than 20,000 genes are expressed in the brain and more than 300 potential post-translational modifications have been determined [95]. Further, there is a wide dynamic range in regard to the relative abundance of proteins in brain cells and tissues or in response to external factors. 
Consequently, the exact molecular etiology as well as the distinct description of most psychiatric disorders is still not well defined. Therefore, there is a dire need for discovery of new proteins [54,96-99] and of molecular biomarkers to categorize, prognosticate, monitor or treat psychiatric disorders [44]. Another challenge is the existence of adequate model systems that mimic exactly the pathophysiological situations taking place in the brain. It is difficult to assess cognitive and neuropsychiatric symptoms such as hallucinations or suicidal ideations in any model organisms. As for human studies, the problem resides in the availability of well-characterized human material taken according to international standard protocols. Further, large pools of samples are required for high-throughput analyses and data, and also due to individual variability. Regarding databases, software or programs used in genomics and proteomics there is a risk that genes and proteins that are well-characterized and described will have a higher detection rate than those with unknown function.

Mass spectrometry can and will most likely play a major role in the identification of psychiatric biomarkers. Several recent developments and innovations have occurred in the field of mass spectrometry in particular and proteomics in general. These include increased machine sensitivity allowing detection of proteins found at low concentrations and improved software allowing not only protein detection, but even the analysis of an entire protein pathway. These advancements make this discipline of increasing potential utility to further the understanding of molecular mechanisms underlying the pathophysiology of psychiatric disorders. Several possible advantages of mass spectrometry exist with regard to possible diagnostic use. For one, mass spectrometry can identify all proteins in a sample, whereas other techniques require that the protein of interest is targeted. Second, analysis of biomaterials such as blood, saliva or urine is convenient and non-invasive (in the case of saliva and urine). Third, the sensitivity of recently developed machinery is extremely high, increasing the potential that peripheral bodily fluids may actually reflect central nervous system protein contents. Finally, protein marker changes could potentially precede behavioral changes, giving an earlier indication of whether a treatment is working. This may be particularly useful in psychiatry, since treatment effects are often not immediately measurable in people with psychiatric problems. The determination of proteome fingerprints or profiles specific to a disorder could open the door to a new way of discovering biomarkers for the diagnosis, prognosis, monitoring and treatment of psychiatric disorders.

Scientists have in some instances thought of biomarkers as a single biomolecule which is differentially expressed in a unique disease. However, as already mentioned above, some psychiatric disorders share similar symptoms and molecular pathways. It may therefore be more appropriate to concentrate on a biomarker signature of multiple molecules which can be altered in order to monitor and identify a psychiatric disorder [100]. Besides examining peripheral and bodily fluids such as the cerebrospinal fluid (CSF) or serum, one could consider, (if available), the use of the primary brain tissue for proteomics experiment. However, to study brain tissue requires a biopsy (available mostly for cancerous tissues or epilepsy) or post-mortem tissue (quality can be sometimes questionable). Further, psychiatry-based proteomics could also investigate protein-protein interactions and protein post-translational modifications (PTMs) as well as the whole proteome. As for the design of the studies, care should be taken to consider high variability in age, gender, demographics, race, postmortem interval, drug treatment, comorbidities and other influencing factors [101]. Another critical point is the evaluation, interpretation and follow-up of results of proteomics studies. Traditionally, validation has been performed with biochemical methods such as western blotting and ELISA. However, these methods are limited by their low highthroughput capability (mostly western blotting) as well as the high cost and difficulty associated with the production of very specific antibodies (ELISA). Fortunately, mass spectrometric methods such as MRM are strong alternatives for the validation of proteins identified in high-throughput proteomics experiments.

\section{Conclusions}

The application of mass spectrometry-based methods opens a new avenue for the investigation of psychiatric disorders with the clear objective of understanding and identifying altered protein pathways as well as uncovering psychiatric biomarkers for diagnosis, prognosis and treatment monitoring. Eventually massspectrometry may facilitate treatment of psychiatric disorders through the identification of therapeutic targets.

\section{Competing interest}

The authors declare that they have no competing and/or financial interests.

\section{Authors' contributions}

AGNW drafted the initial manuscript; based in part on a presentation given by AGW. AGW performed substantive editing and re-writing. All authors contributed to the conceptualisation and interpretation of results and revision of the manuscript, and all authors reviewed and approved the final manuscript.

\section{Acknowledgements}

We would like to thank Ms. Laura Mulderig, Scott Nichols and their colleagues (Waters Corporation) for their generous support in setting up the Proteomics Center at Clarkson University. CCD thanks Drs. Thomas A. Neubert (New York University, Belinda Willard (Cleveland Clinic) and Gregory Wolber \& David Mclaughin (Eastman Kodak Company) for donation of a 
TofSpec2E MALDI-MS (each). This work was supported in part by Clarkson University (start-up grant to CCD), private donations (Ms. Mary Stewart Joyce, Mr. Kenneth Sandler), the Redcay Foundation (SUNY Plattsburgh), the University of Rostock, the Alexander von Humboldt Foundation, SciFund Challenge Donors and by the U.S. Army research office through the Defense University Research Instrumentation Program (DURIP grant \#W91 1NF-11-10304).

\section{Author details}

'Biochemistry and Proteomics Group, Department of Chemistry and Biomolecular Science, Clarkson University, 8 Clarkson Avenue, Potsdam, NY 13699-5810, USA. ²Department of Psychiatry, University of Rostock, Gehlsheimer Straße 20, Rostock D-18147, Germany. ${ }^{3}$ College of Medicine, Swansea University, Singleton Park, Swansea SA2 8PP, UK. ${ }^{4}$ Neuropsychology Clinic and Psychoeducation Services, SUNY Plattsburgh, 101 Broad St, Plattsburgh 12901, NY.

Received: 22 October 2012 Accepted: 12 February 2013

Published: 5 June 2013

\section{References}

1. Alawieh A, Zaraket FA, Li JL, Mondello S, Nokkari A, Razafsha M, Fadlallah B, Boustany RM, Kobeissy FH: Systems biology, bioinformatics, and biomarkers in neuropsychiatry. Front Neurosci 2012, 6:187.

2. Woods AG, Sokolowska I, Taurines R, Gerlach M, Dudley E, Thome J, Darie CC: Potential biomarkers in psychiatry: focus on the cholesterol system. J Cell Mol Med 2012, 16(6):1184-1195.

3. Herberth M, Koethe D, Levin Y, Schwarz E, Krzyszton ND, Schoeffmann S, Ruh H, Rahmoune H, Kranaster L, Schoenborn T, et al: Peripheral profiling analysis for bipolar disorder reveals markers associated with reduced cell survival. Proteomics 2011, 11(1):94-105.

4. Kurian SM, Le-Niculescu H, Patel SD, Bertram D, Davis J, Dike C, Yehyawi N, Lysaker P, Dustin J, Caligiuri M, et al: Identification of blood biomarkers for psychosis using convergent functional genomics. Mol Psychiatry 2011, 16(1):37-58.

5. Le-Niculescu H, McFarland MJ, Ogden CA, Balaraman Y, Patel S, Tan J, Rodd ZA, Paulus M, Geyer MA, Edenberg HJ, et al: Phenomic, convergent functional genomic, and biomarker studies in a stress-reactive genetic animal model of bipolar disorder and co-morbid alcoholism. Am J Med Genetics 2008, 147B(2):134-166.

6. Schmidt HD, Shelton RC, Duman RS: Functional biomarkers of depression: diagnosis, treatment, and pathophysiology. Neuropsychopharmacol 2011, 36(12):2375-2394.

7. Desai AP, Stanley T, Atuan M, McKey J, Lipuma JJ, Rogers B, Jerris R: Use of matrix assisted laser desorption ionisation-time of flight mass spectrometry in a paediatric clinical laboratory for identification of bacteria commonly isolated from cystic fibrosis patients. J Clin Pathol 2012, 65(9):835-838.

8. Wang XH, Zhang G, Fan YY, Yang X, Sui WJ, Lu XX: Direct identification of bacteria causing urinary tract infections by combining matrix-assisted laser desorption ionization-time of flight mass spectrometry with UF-1000i urine flow cytometry. J Microbiol Meth 2013, 92(3):231-235.

9. Kok K, Chen SC, Dwyer DE, Iredell JR: Current status of matrix-assisted laser desorption ionisation-time of flight mass spectrometry in the clinical microbiology laboratory. Pathology 2013, 45(1):4-17.

10. Rhea JM, Ritchie JC, Molinaro RJ: Development of a liquid chromatography tandem mass spectrometry method for iothalamate measurement to assess renal function for potential kidney donation. Clin Chim Acta 2012. doi:10.1016/j.cca.2012.12.003. pii:S0009-8981(12)005736. [Epub ahead of print].

11. Chace DH, Spitzer AR: Altered metabolism and newborn screening using tandem mass spectrometry: lessons learned from the bench to bedside. Curr Pharm Biotechnol 2011, 12(7):965-975.

12. Ozben T: Expanded newborn screening and confirmatory follow-up testing for inborn errors of metabolism detected by tandem mass spectrometry. Clinical chemistry and laboratory medicine : CCLM / FESCC 2013, 51(1):157-176.

13. Chung L, Baxter RC: Breast cancer biomarkers: proteomic discovery and translation to clinically relevant assays. Expert Rev Proteom 2012, 9(6):599-614.
14. Chung L, Shibli S, Moore K, Elder EE, Boyle FM, Marsh DJ, Baxter RC: Tissue biomarkers of breast cancer and their association with conventional pathologic features. Br J Cancer 2013, 108(2):351-60.

15. Pin E, Fredolini C, Petricoin EF 3rd: Proteomics role in prostate cancer biomarkers discovery and validation. Clinical Biochem 2012, 46:524-538.

16. Shi M, Sui YT, Peskind ER, Li G, Hwang H, Devic I, Ginghina C, Edgar JS, Pan C, Goodlett DR, et al: Salivary tau species are potential biomarkers of Alzheimer's disease. JAD 2011, 27(2):299-305.

17. Gibbons GH, Liew CC, Goodarzi MO, Rotter Jl, Hsueh WA, Siragy HM, Pratt R, Dzau VJ: Genetic markers: progress and potential for cardiovascular disease. Circulation 2004, 109(25 Suppl 1):IV47-IV58.

18. Wu T, McGrath KC, Death AK: Cardiovascular disease in diabetic nephropathy patients: cell adhesion molecules as potential markers? Vasc Health Risk Manag 2005, 1(4):309-316.

19. Kessler RC, Demler O, Frank RG, Olfson M, Pincus HA, Walters EE, Wang P, Wells KB, Zaslavsky AM: Prevalence and treatment of mental disorders, 1990 to 2003. N Engl J Med 2005, 352(24):2515-2523.

20. Abdolmaleky HM, Cheng KH, Russo A, Smith CL, Faraone SV, Wilcox M, Shafa R, Glatt SJ, Nguyen G, Ponte JF, et al: Hypermethylation of the reelin (RELN) promoter in the brain of schizophrenic patients: a preliminary report. Am J Med Genetics 2005, 134B(1):60-66.

21. Abdolmaleky HM, Thiagalingam S, Wilcox M: Genetics and epigenetics in major psychiatric disorders: dilemmas, achievements, applications, and future scope. Am J Pharmacogenomics 2005, 5(3):149-160.

22. Kundakovic M, Chen $Y$, Guidotti A, Grayson DR: The reelin and GAD67 promoters are activated by epigenetic drugs that facilitate the disruption of local repressor complexes. Mol Pharmacol 2009, 75(2):342-354.

23. Guidotti A, Auta J, Davis JM, Di-Giorgi-Gerevini V, Dwivedi Y, Grayson DR, Impagnatiello F, Pandey G, Pesold C, Sharma R, et al: Decrease in reelin and glutamic acid decarboxylase67 (GAD67) expression in schizophrenia and bipolar disorder: a postmortem brain study. Arch Gen Psychiatry 2000, 57(11):1061-1069.

24. Lochman J, Balcar VJ, Stastny F, Sery O: Preliminary evidence for association between schizophrenia and polymorphisms in the regulatory Regions of the ADRA2A, DRD3 and SNAP-25 Genes. Psychiatry Res 2012, 205(1-2):7-12

25. Lundstrom K, Turpin MP: Proposed schizophrenia-related gene polymorphism: expression of the Ser9Gly mutant human dopamine D3 receptor with the Semliki Forest virus system. Biochem Biophys Res Commun 1996, 225(3):1068-1072.

26. Clark D, Dedova I, Cordwell S, Matsumoto I: Altered proteins of the anterior cingulate cortex white matter proteome in schizophrenia. Proteomics Clin Appl 2007, 1(2):157-166.

27. Carroll LS, Kendall K, O'Donovan MC, Owen MJ, Williams NM: Evidence that putative ADHD low risk alleles at SNAP25 may increase the risk of schizophrenia. Am J Med Genetics 2009, 150B(7):893-899.

28. Cole BJ, Cador M, Stinus L, Rivier J, Vale W, Koob GF, Le Moal M: Central administration of a CRF antagonist blocks the development of stressinduced behavioral sensitization. Brain Res 1990, 512(2):343-346.

29. Sarnyai Z, Hohn J, Szabo G, Penke B: Critical role of endogenous corticotropin-releasing factor (CRF) in the mediation of the behavioral action of cocaine in rats. Life Sci 1992, 51(26):2019-2024.

30. Sarnyai Z, Shaham Y, Heinrichs SC: The role of corticotropin-releasing factor in drug addiction. Pharmacol Rev 2001, 53(2):209-243.

31. Cador M, Cole BJ, Koob GF, Stinus L, Le Moal M: Central administration of corticotropin releasing factor induces long-term sensitization to D-amphetamine. Brain Res 1993, 606(2):181-186.

32. Koob G, Kreek MJ: Stress, dysregulation of drug reward pathways, and the transition to drug dependence. Am J Psychiatry 2007, 164(8):1149-1159.

33. Jacka FN, Maes M, Pasco JA, Williams $\sqcup$, Berk M: Nutrient intakes and the common mental disorders in women. J Affect Disord 2012, 141(1):79-85.

34. Kodydkova J, Vavrova L, Zeman M, Jirak R, Macasek J, Stankova B, Tvrzicka E, Zak A: Antioxidative enzymes and increased oxidative stress in depressive women. Clin Biochem 2009, 42(13-14):1368-1374.

35. Maes M, De Vos N, Pioli R, Demedts P, Wauters A, Neels H, Christophe A: Lower serum vitamin $E$ concentrations in major depression. Another marker of lowered antioxidant defenses in that illness. J Affect Disord 2000, 58(3):241-246.

36. Maes M, Mihaylova I, Kubera M, Uytterhoeven M, Vrydags N, Bosmans E: Lower plasma Coenzyme Q10 in depression: a marker for treatment 
resistance and chronic fatigue in depression and a risk factor to cardiovascular disorder in that illness. Neuro Endocrinol Lett 2009, 30(4):462-469

37. Pasco JA, Jacka FN, Williams $L$, Evans-Cleverdon M, Brennan SL, Kotowicz MA, Nicholson GC, Ball MJ, Berk M: Dietary selenium and major depression: a nested case-control study. Complement Ther Med 2012, 20(3):119-123

38. Szewczyk B, Kubera M, Nowak G: The role of zinc in neurodegenerative inflammatory pathways in depression. Prog Neuropsychopharmacol Biol Psychiatry 2011, 35(3):693-701.

39. Del Campo N, Chamberlain SR, Sahakian BJ, Robbins TW: The roles of dopamine and noradrenaline in the pathophysiology and treatment of attention-deficit /hyperactivity disorder. Biol Psychiatry 2011, 69(12):e145-e157.

40. Cortese S: The neurobiology and genetics of Attention-Deficit /Hyperactivity Disorder (ADHD): what every clinician should know. Eu J Paed Neurol 2012, 16(5):422-433.

41. Spencer TJ, Biederman J, Madras BK, Faraone SV, Dougherty DD, Bonab AA Fischman AJ: In vivo neuroreceptor imaging in attention-deficit /hyperactivity disorder: a focus on the dopamine transporter. Biol Psychiatry 2005, 57(11):1293-1300.

42. Scassellati C, Bonvicini C, Faraone SV, Gennarelli M: Biomarkers and attention-deficit/hyperactivity disorder: a systematic review and metaanalyses. J Am Acad Child Adolesc Psychiatry 2012, 51(10):1003-1019. e1020.

43. Unlu M, Morgan ME, Minden JS: Difference gel electrophoresis: a single gel method for detecting changes in protein extracts. Electrophoresis 1997, 18(11):2071-2077.

44. Filiou MD, Turck CW, Martins-de-Souza D: Quantitative proteomics for investigating psychiatric disorders. Proteomics Clin Appl 2011, 5(1-2):38-49.

45. Ditzen C, Jastorff AM, Kessler MS, Bunck M, Teplytska L, Erhardt A, Kromer SA, Varadarajulu J, Targosz BS, Sayan-Ayata EF, et al: Protein biomarkers in a mouse model of extremes in trait anxiety. Mol Cell Proteomics 2006, 5(10):1914-1920.

46. Kekesi KA, Juhasz G, Simor A, Gulyassy P, Szego EM, Hunyadi-Gulyas E, Darula Z, Medzihradszky KF, Palkovits M, Penke B, et al: Altered functional protein networks in the prefrontal cortex and amygdala of victims of suicide. PLoS One 2012, 7(12):e50532.

47. Mu J, Xie P, Yang ZS, Yang DL, Lv FJ, Luo TY, Li Y: Neurogenesis and major depression: implications from proteomic analyses of hippocampa proteins in a rat depression model. Neurosci Lett 2007, 416(3):252-256.

48. Martins-de-Souza D, Guest PC, Harris LW, Vanattou-Saifoudine N, Webster MJ, Rahmoune H, Bahn S: Identification of proteomic signatures associated with depression and psychotic depression in post-mortem brains from major depression patients. Transl Psychiatry 2012, 2:e87.

49. Smith KM, Renshaw PF, Bilello J: The diagnosis of depression: current and emerging methods. Comprehen Psychiatry 2013, 54(1):1-6.

50. Takahashi M, Hayashi H, Watanabe Y, Sawamura K, Fukui N, Watanabe J, Kitajima T, Yamanouchi Y, Iwata N, Mizukami K, et al: Diagnostic classification of schizophrenia by neural network analysis of blood-based gene expression signatures. Schizophr Res 2010, 119(1-3):210-218.

51. Ngounou Wetie AG, Sokolowska I, Woods AG, Wormwood KL, Dao S, Patel S, Clarkson BD, Darie CC: Automated Mass Spectrometry-Based Functional Assay for the Routine Analysis of the Secretome. J Lab Autom 2012, 18(1): 19-29.

52. Woods AG, Sokolowska I, Yakubu R, Butkiewicz M, LaFleur M, Talbot C, Darie CC: Blue native page and mass spectrometry as an approach for the investigation of stable and transient protein-protein interactions. In Oxidative Stress: Diagnostics, Prevention, and Therapy. Edited by Andreescu S, Hepel M. Washington, D.C: American Chemical Society; 2011.

53. Darie CC, Deinhardt K, Zhang G, Cardasis HS, Chao MV, Neubert TA: Identifying transient protein-protein interactions in EphB2 signaling by blue native PAGE and mass spectrometry. Proteomics 2011, 11(23):4514-4528.

54. Sokolowska I, Woods AG, Wagner J, Dorler J, Wormwood K, Thome J, Darie CC: Mass spectrometry for proteomics-based investigation of oxidative stress and heat shock proteins. In Oxidative Stress: Diagnostics, Prevention, and Therapy. Edited by Andreescu S, Hepel M. Washington, D.C: American Chemical Society; 2011.

55. Holcapek M, Schoenmakers PJ: Mass spectrometry: innovation and application. Part VI. J Chromatogr A 2010, 1217(25):3907.

56. Jirasko R, Holcapek M: Structural analysis of organometallic compounds with soft ionization mass spectrometry. Mass Spectrom Rev 2011 30(6):1013-1036
57. O'Farrell PH: High resolution two-dimensional electrophoresis of proteins. J Biol Chem 1975, 250(10):4007-4021.

58. Darie CC, Shetty V, Spellman DS, Zhang G, Xu C, Cardasis HL, Blais S, Fenyo D, Neubert TA: Blue Native PAGE and mass spectrometry analysis of the ephrin stimulation- dependent protein-protein interactions in NG108-EphB2 cells. Düsseldorf, Germany: Springer-Verlag; 2008.

59. Darie CC, Biniossek ML, Gawinowicz MA, Milgrom Y, Thumfart JO, Jovine L, Litscher ES, Wassarman PM: Mass spectrometric evidence that proteolytic processing of rainbow trout egg vitelline envelope proteins takes place on the egg. J Biol Chem 2005, 280(45):37585-37598.

60. Darie CC, Biniossek ML, Jovine L, Litscher ES, Wassarman PM: Structural characterization of fish egg vitelline envelope proteins by mass spectrometry. Biochem 2004, 43(23):7459-7478.

61. Darie CC, Biniossek ML, Winter V, Mutschler B, Haehnel W: Isolation and structural characterization of the Ndh complex from mesophyll and bundle sheath chloroplasts of Zea mays. FEBS J 2005, 272(11):2705-2716.

62. Darie CC, Litscher ES, Wassarman PM: Structure, processing, and polymerization of rainbow trout egg vitelline envelope proteins. Düsseldorf, Germany: Springer-Verlag; 2008.

63. Sokolowska I, Gawinowicz MA, Ngounou Wetie AG, Darie CC: Disulfide proteomics for identification of extracellular or secreted proteins. Electrophoresis 2012, 33(16):2527-2536.

64. Sokolowska I, Dorobantu C, Woods AG, Macovei A, Branza-Nichita N, Darie CC: Proteomic analysis of plasma membranes isolated from undifferentiated and differentiated HepaRG cells. Proteome Sci 2012, 10(1):47.

65. Gorg A, Weiss W, Dunn MJ: Current two-dimensional electrophoresis technology for proteomics. Proteomics 2004, 4(12):3665-3685.

66. Aebersold R, Goodlett DR: Mass spectrometry in proteomics. Chem Rev 2001, 101(2):269-295.

67. Sokolowska I, Ngounou Wetie AG, Woods AG, Darie CC: Automatic Determination of Disulfide Bridges in Proteins. J Lab Autom 2012, 17(6):408-16.

68. Woods AG, Sokolowska I, Darie CC: Identification of consistent alkylation of cysteine-less peptides in a proteomics experiment. Biochem Biophys Res Commun 2012, 419(2):305-308.

69. Gant-Branum RL, Kerr TJ, McLean JA: Labeling strategies in mass spectrometry-based protein quantitation. Analyst 2009, 134(8):1525-1530

70. Ross PL, Huang YN, Marchese JN, Williamson B, Parker K, Hattan S, Khainovski N, Pillai S, Dey S, Daniels S, et al: Multiplexed protein quantitation in Saccharomyces cerevisiae using amine-reactive isobaric tagging reagents. Mol Cell Proteomics 2004, 3(12):1154-1169.

71. Martin B, Brenneman R, Becker KG, Gucek M, Cole RN, Maudsley S: iTRAQ analysis of complex proteome alterations in 3xTgAD Alzheimer's mice: understanding the interface between physiology and disease. PLOS One 2008, 3(7):e2750.

72. Gygi SP, Rist B, Gerber SA, Turecek F, Gelb MH, Aebersold R: Quantitative analysis of complex protein mixtures using isotope-coded affinity tags. Nat Biotechnol 1999, 17(10):994-999.

73. Mann M: Functional and quantitative proteomics using SILAC. Nat Rev Mol Cell Biol 2006, 7(12):952-958.

74. Spellman DS, Deinhardt K, Darie CC, Chao MV, Neubert TA: Stable isotopic labeling by amino acids in cultured primary neurons: application to brain-derived neurotrophic factor-dependent phosphotyrosineassociated signaling. Mol Cell Proteomics 2008, 7(6):1067-1076.

75. Jin J, Meredith GE, Chen L, Zhou Y, XU J, Shie FS, Lockhart P, Zhang J: Quantitative proteomic analysis of mitochondrial proteins: relevance to Lewy body formation and Parkinson's disease. Brain Res Mol Brain Res 2005, 134(1):119-138.

76. Choe L, D'Ascenzo M, Relkin NR, Pappin D, Ross P, Williamson B, Guertin S, Pribil $\mathrm{P}$, Lee $\mathrm{KH}$ : 8-plex quantitation of changes in cerebrospinal fluid protein expression in subjects undergoing intravenous immunoglobulin treatment for Alzheimer's disease. Proteomics 2007, 7(20):3651-3660.

77. Anderson L, Hunter CL: Quantitative mass spectrometric multiple reaction monitoring assays for major plasma proteins. Mol Cell Proteomics 2006, 5(4):573-588.

78. Corr JJ, Kovarik P, Schneider BB, Hendrikse J, Loboda A, Covey TR: Design considerations for high speed quantitative mass spectrometry with MALDI ionization. J Am Soc Mass Spectrom 2006, 17(8):1129-1141.

79. Volmer DA, Sleno L, Bateman K, Sturino C, Oballa R, Mauriala T, Corr J: Comparison of MALDI to ESI on a triple quadrupole platform for pharmacokinetic analyses. Analyt Chem 2007, 79(23):9000-9006. 
80. Dowsey AW, Dunn MJ, Yang GZ: The role of bioinformatics in twodimensional gel electrophoresis. Proteomics 2003, 3(8):1567-1596.

81. Malik R, Dulla K, Nigg EA, Korner R: From proteome lists to biological impact-tools and strategies for the analysis of large MS data sets. Proteomics 2010, 10(6):1270-1283.

82. Song F, Poljak A, Smythe GA, Sachdev P: Plasma biomarkers for mild cognitive impairment and Alzheimer's disease. Brain Res Rev 2009, 61(2):69-80.

83. Edgar PF, Schonberger SJ, Dean B, Faull RL, Kydd R, Cooper GJ: A comparative proteome analysis of hippocampal tissue from schizophrenic and Alzheimer's disease individuals. Mol Psychiatry 1999, 4(2):173-178

84. Johnston-Wilson NL, Sims CD, Hofmann JP, Anderson L, Shore AD, Torrey $\mathrm{EF}$, Yolken $\mathrm{RH}$ : Disease-specific alterations in frontal cortex brain proteins in schizophrenia, bipolar disorder, and major depressive disorder. The Stanley Neuropathology Consortium. Mol Psychiatry 2000, 5(2):142-149.

85. Prabakaran S, Swatton JE, Ryan MM, Huffaker SJ, Huang JT, Griffin JL, Wayland M, Freeman T, Dudbridge F, Lilley KS, et al: Mitochondrial dysfunction in schizophrenia: evidence for compromised brain metabolism and oxidative stress. Mol Psychiatry 2004, 9(7):684-697. 643

86. Beasley CL, Pennington K, Behan A, Wait R, Dunn MJ, Cotter D: Proteomic analysis of the anterior cingulate cortex in the major psychiatric disorders: Evidence for disease-associated changes. Proteomics 2006, 6(11):3414-3425

87. Clark D, Dedova I, Cordwell S, Matsumoto I: A proteome analysis of the anterior cingulate cortex gray matter in schizophrenia. Mol Psychiatry 2006, 11(5):459-470. 423.

88. Novikova SI, He F, Cutrufello NJ, Lidow MS: Identification of protein biomarkers for schizophrenia and bipolar disorder in the postmortem prefrontal cortex using SELDI-TOF-MS ProteinChip profiling combined with MALDI-TOF-PSD-MS analysis. Neurobio/ Dis 2006, 23(1):61-76.

89. Pennington $\mathrm{K}$, Beasley $\mathrm{CL}$, Dicker P, Fagan A, English J, Pariante CM, Wait R, Dunn MJ, Cotter DR: Prominent synaptic and metabolic abnormalities revealed by proteomic analysis of the dorsolateral prefrontal cortex in schizophrenia and bipolar disorder. Mol Psychiatry 2008, 13(12):1102-1117.

90. Sivagnanasundaram S, Crossett B, Dedova I, Cordwell S, Matsumoto I: Abnormal pathways in the genu of the corpus callosum in schizophrenia pathogenesis: a proteome study. Proteomics Clin App/ 2007, 1(10):1291-1305.

91. Behan AT, Byrne C, Dunn MJ, Cagney G, Cotter DR: Proteomic analysis of membrane microdomain-associated proteins in the dorsolateral prefrontal cortex in schizophrenia and bipolar disorder reveals alterations in LAMP, STXBP1 and BASP1 protein expression. Mol Psychiatry 2009, 14(6):601-613.

92. Noguchi T, Makino S, Matsumoto R, Nakayama S, Nishiyama M, Terada Y, Hashimoto K: Regulation of glucocorticoid receptor transcription and nuclear translocation during single and repeated immobilization stress. Endocrinology 2010, 151(9):4344-4355.

93. Schwanhausser B, Busse D, Li N, Dittmar G, Schuchhardt J, Wolf J, Chen W, Selbach M: Global quantification of mammalian gene expression control. Nature 2011, 473(7347):337-342.

94. Pajer K, Andrus BM, Gardner W, Lourie A, Strange B, Campo J, Bridge J, Blizinsky K, Dennis K, Vedell P, et al: Discovery of blood transcriptomic markers for depression in animal models and pilot validation in subjects with early-onset major depression. Transl Psychiatry 2012, 2:e101.

95. English JA, Pennington K, Dunn MJ, Cotter DR: The neuroproteomics of schizophrenia. Biol Psychiatry 2011, 69(2):163-172.

96. Roy U, Sokolowska I, Woods AG, Darie CC: Structural Investigation of Tumor Differentiation Factor (TDF). Biotechnol Appl Biochem 2012. EPub Ahead of Print.

97. Sokolowska I, Woods AG, Gawinowicz MA, Roy U, Darie CC: Identification of a potential tumor differentiation factor receptor candidate in prostate cancer cells. FEBS J 2012, 279(14):2579-2594.

98. Sokolowska I, Woods AG, Gawinowicz MA, Roy U, Darie CC: Identification of potential tumor differentiation factor (TDF) receptor from steroidresponsive and steroid-resistant breast cancer cells. J Biol Chem 2012, 287(3):1719-1733.
99. Sokolowska I, Woods AG, Gawinowicz MA, Roy U, Darie CC Characterization of Tumor Differentiation Factor (TDF) and its receptor (TDF-R). Cell Mol Life Sci 2012. EPub Ahead of Print.

100. Pies R: Beyond reliability: biomarkers and validity in psychiatry. Psychiatry 2008, 5(1):48-52.

101. English JA, Dicker P, Focking M, Dunn MJ, Cotter DR: 2-D DIGE analysis implicates cytoskeletal abnormalities in psychiatric disease. Proteomics 2009, 9(12):3368-3382.

doi:10.1186/2049-9256-1-8

Cite this article as: Ngounou Wetie et al:: Mass spectrometry for the detection of potential psychiatric biomarkers. Journal of Molecular Psychiatry 2013 1:8.

\section{Submit your next manuscript to BioMed Central and take full advantage of:}

- Convenient online submission

- Thorough peer review

- No space constraints or color figure charges

- Immediate publication on acceptance

- Inclusion in PubMed, CAS, Scopus and Google Scholar

- Research which is freely available for redistribution 